\title{
Plasmid-encapsulated polyethylene glycol-grafted polyethylenimine nanoparticles for gene delivery into rat mesenchymal stem cells
}

This article was published in the following Dove Press journal:

International Journal of Nanomedicine

20 April 20II

Number of times this article has been viewed

\author{
Xiao-Ai Chen ${ }^{1,5^{*}}$ \\ Li-Jun Zhang ${ }^{2 *}$ \\ Zhi-Jie $\mathrm{He}^{3}$ \\ Wei-Wei Wang ${ }^{4}$ \\ Bo Xu' \\ Qian Zhong' \\ Xin-Tao Shuai ${ }^{4}$ \\ Li-Qun Yang ${ }^{4}$ \\ Yu-Bin Deng' \\ 'Department of Pathophysiology, \\ Zhongshan School of Medicine, Sun \\ Yat-sen University, Guangzhou, China; \\ ${ }^{2}$ Futian Affiliated Hospital, Guangdong \\ Medical College, Shenzhen, China; ${ }^{3}$ Sun \\ Yat-sen Memorial Hospital, Sun \\ Yat-sen University, Guangzhou, China; \\ ${ }^{4}$ Institute of Polymer Science, School \\ of Chemistry and Chemical \\ Engineering, BME Center, State Key \\ Laboratory of Optoelectronic \\ Materials and Technologies, Sun Yat- \\ sen University, Guangzhou, China; \\ ${ }^{5}$ Yunnan Cancer Hospital, The Third \\ Affiliated Hospital, Kunming Medical \\ College, Kunming, China
}

*Both authors contributed equally to this work

Correspondence: Yu-Bin Deng

Department of Pathophysiology,

Zhongshan School of Medicine,

Sun Yat-sen University, Guangzhou, China

Tel +86-13168348|62

Email dengyub@mail.sysu.edu.cn
Background: Mesenchymal stem cell transplantation is a promising method in regenerative medicine. Gene-modified mesenchymal stem cells possess superior characteristics of specific tissue differentiation, resistance to apoptosis, and directional migration. Viral vectors have the disadvantages of potential immunogenicity, carcinogenicity, and complicated synthetic procedures. Polyethylene glycol-grafted polyethylenimine (PEG-PEI) holds promise in gene delivery because of easy preparation and potentially targeting modification.

Methods: A PEG8k-PEI25k graft copolymer was synthesized. Agarose gel retardation assay and dynamic light scattering were used to determine the properties of the nanoparticles. MTT reduction, wound and healing, and differentiation assays were used to test the cytobiological characteristics of rat mesenchymal stem cells, fluorescence microscopy and flow cytometry were used to determine transfection efficiency, and atomic force microscopy was used to evaluate the interaction between PEG-PEI/plasmid nanoparticles and mesenchymal stem cells.

Results: After incubation with the copolymer, the bionomics of mesenchymal stem cells showed no significant change. The mesenchymal stem cells still maintained high viability, resettled the wound area, and differentiated into adipocytes and osteoblasts. The PEG-PEI completely packed plasmid and condensed plasmid into stable nanoparticles of 100-150 nm diameter. After optimizing the N/P ratio, the PEG-PEI/plasmid microcapsules delivered plasmid into mesenchymal stem cells and obtained an optimum transfection efficiency of $15 \%-21 \%$, which was higher than for cationic liposomes.

Conclusion: These data indicate that PEG-PEI is a valid gene delivery agent and has better transfection efficiency than cationic liposomes in mesenchymal stem cells.

Keywords: stem cells, gene delivery, nanoparticles, atomic force microscopy

\section{Introduction}

Stem cells are clonal precursors of nonhematopoietic tissue, and possess the capability of self-renewal and differentiation into various tissue cells, such as osteoblasts, ${ }^{1}$ chondrocytes, ${ }^{2}$ astrocytes, ${ }^{3}$ neurons, ${ }^{4}$ and adipocytes. ${ }^{5}$ Among several categories of stem cells, mesenchymal stem cells are used widely in regenerative medicine because of their multilineage differentiation, ${ }^{6}$ secretion of many cytokines and trophic factors, ${ }^{7}$ low immunogenicity, ${ }^{8}$ and freedom from ethical controversy. Mesenchymal stem cells can be safely introduced into the brain, migrate directionally towards injured tissue, and can promote functional recovery. ${ }^{9}$ Transplanted mesenchymal stem cells are currently under intensive investigation in regenerative medicine as potential cell-based therapies for neurological diseases or injuries. ${ }^{10}$ Gene-modified mesenchymal stem 
cells possess superior characteristics of specific tissue differentiation, ${ }^{11}$ resistance to apoptosis, ${ }^{12}$ and directional migration. $^{13}$

Viral gene delivery vectors, such as retroviruses, adenoviruses, and adeno-associated viruses, are extensively used for gene delivery and show superior transfection efficiency. ${ }^{14,15}$ However, viral vectors have shown the disadvantages of potential immunogenicity and carcinogenicity, and have a complicated synthesis procedure. Recently, nonviral gene vectors, including liposomes and cationic polymers, have received great attention because of their easy preparation, lack of immunogenicity, and ability to be modified for potential targeted delivery. ${ }^{16-18}$ Among the cationic polymers, polyethylenimine was reported to be an effective transfection reagent due to easy synthesis and multiple modifications. ${ }^{19,20}$ Polyethylenimine concentrates negatively charge DNA via electrostatic interaction and form polyethylenimine/DNA nanoparticles. They enter nuclei through several steps, including cellular uptake, escaping from nucleases, endosomal release, and DNA decondensation inside nuclei. ${ }^{21}$

However, excessive usage of polyethylenimine results in high cytotoxicity, which is the major limitation in polyethylenimine-mediated gene delivery. ${ }^{22}$ Furthermore, serum-free culture media is preferred in transfection experiments in vitro to avoid the interaction between polyethylenimine and serum protein. In addition, serum deprivation could induce apoptosis of mesenchymal stem cells. ${ }^{23}$ Therefore, covalent linkage with nonionic and hydrophilic polymers, such as polyethylene glycol, has been used to minimize the toxicity of polyethylenimine. ${ }^{24-26}$ Polyethylene glycol has also improved the solubility of polyethylene glycol-grafted polyethylenimine (PEG-PEI) complexes, minimized aggregation, and reduced nonspecific interactions with proteins in physiological fluids. ${ }^{27-29}$

To our knowledge, there are few studies reported on the use of PEG-PEI to prepare PEG-PEI/DNA nanoparticles for gene delivery into mesenchymal stem cells. In this work, PEG-PEI was synthesized, and its toxicity and biocompatibility were evaluated by MTT, wound and healing, and cell differentiation assays using mesenchymal stem cells. Plasmid-encapsulated PEG-PEI (PEG-PEI/plasmid) nanoparticles were prepared, and their properties were investigated by agarose gel retardation assay and dynamic light scattering analysis. The gene transfection efficiency was assessed by inverted fluorescence microscopy and flow cytometry. The interaction between plasmid-encapsulated PEG-PEI nanoparticles and rat mesenchymal stem cells was studied by atomic force microscopy.

\section{Materials and methods \\ Materials}

Polyethylenimine with a molecular weight of $25 \mathrm{kDa}$ was bought from Sigma-Aldrich (St Louis, MO). 3-(4,5dimethylthiazol-2-yl)-2,5-diphenyltetrazolium bromide (MTT) and Dulbecco's modified Eagle's medium/F-12 (DMEM) were obtained from Gibco (Gibco, Carlsbad, CA). Adipogenic and osteogenic media were bought from Cyagen Biosciences, China. PureYield ${ }^{\mathrm{TM}}$ Plasmid Midi Prep System was bought from Promega (Madison, WI). Lipofectamine ${ }^{\mathrm{TM}}$ was bought from Beyotime Institute of Biotechnology, China.

\section{Synthesis and characterization of PEG8k-PEI25k}

Methoxy $N$-hydroxysuccinimide polyethylene glycol (mPEG2k-NHS) was synthesized according to our previous work. ${ }^{30}$ PEG8k-PEI25k was synthesized by adding $1.25 \mathrm{~g}$ of hyperbranched polyethylenimine and $0.5 \mathrm{~g}$ of $\mathrm{mPEG}-\mathrm{NHS}$ to phosphate-buffered saline ( $\mathrm{pH} 7.4$ ), and the solution was magnetically stirred at room temperature overnight. The resulting solution was purified by membrane dialysis (molecular weight cutoff $3.5 \mathrm{kDa}$ ) in distilled water for 48 hours, and then lyophilized to obtain PEG8k-PEI25k. PEG-PEI was characterized by ${ }^{1} \mathrm{H}-\mathrm{NMR}$ (Varian Mercury 300-mHz NMR spectrometer, Mountain View, CA) in deuterium oxide. Fourier transform infrared measurement was carried out using a Fourier transform infrared analyzer (Nicolet/Nexus 670, Woodland, CA) at a resolution of $4 \mathrm{~cm}^{-1}$ using the $\mathrm{KBr}$ method.

\section{Preparation and properties of plasmid- encapsulated PEG-PEI nanoparticles}

\section{Preparation}

The plasmid-enhanced green fluorescent protein (pEGFP-C1, $4.7 \mathrm{~kb}$ ) was expanded in Escherichia coli (E. coli strain DH5 $\alpha$ ) and purified with the Plasmid Midi Prep System following the manufacturer's protocol. The quantity and quality of the purified plasmid were assessed by optical density at $260 \mathrm{~nm}$ and $280 \mathrm{~nm}$, and by electrophoresis in $0.8 \%$ agarose gel. The purified plasmid was resuspended in ultrapure water and kept in aliquots at a concentration of $0.7 \mathrm{mg} / \mathrm{mL}$. The plasmid solution, and the desired amount of PEG-PEI solution in accord with the required N/P ratio (molar ratio of the positive amino groups of polyethylenimine to the phosphoric anions of plasmid) were separately diluted with $0.9 \% \mathrm{NaCl}$ to $100 \mu \mathrm{L}$. The copolymer solution was then 
added to the plasmid solution and mixed by incubating at $200 \mathrm{rpm}$ at room temperature for 30 minutes. The complexes obtained were kept standing at room temperature for 30 minutes before use.

\section{Agarose gel retardation assay}

To condense $1 \mu \mathrm{g}$ of plasmid, the plasmid-encapsulated PEG-PEI complexes were prepared at designated $\mathrm{N} / \mathrm{P}$ ratios of $0,0.5,1,1.5,2,2.5,3$, and 4 without dilution. Loading buffer was added to the samples. The samples were loaded onto $0.8 \%$ agarose gel stained with $3 \mu \mathrm{L}$ ethidium bromide solution $(10 \mu \mathrm{g} / \mu \mathrm{L})$, and electrophoresed at $90 \mathrm{~V}$ for 45 minutes. An ultraviolet image station (Olympus, Japan) was used to record the gel images.

\section{Dynamic light scattering analysis}

To condense $1 \mu \mathrm{g}$ of plasmid, plasmid-encapsulated PEG-PEI was prepared at designated $\mathrm{N} / \mathrm{P}$ ratios of $0,0.5,1,1.5,2,2.5$, $3,4,5,7,10,15,20,25$, and 30 . The plasmid solution and the desired amount of PEG-PEI solution in accord with the required N/P ratio were separately diluted with ultrapure water to $100 \mu \mathrm{L}$. The copolymer solution was then added to the plasmid solution and mixed by incubation at $200 \mathrm{rpm}$ and room temperature for 30 minutes in order to form complexes. The size of the nanoparticles was determined by a Zetasizer 3000HS (Malvern, UK) at specified time intervals at room temperature. Samples were run in triplicate.

\section{Cytobiological assessment of rat mesenchymal stem cells}

\section{Cell culture}

The rat mesenchymal stem cells were harvested from the femurs and tibias of four-week-old (about $60 \mathrm{~g}$ ) female Sprague-Dawley rats (Center of Experimental Animal of Sun Yat-sen University, Guangzhou). The rats were sacrificed by cervical dislocation. Briefly, the bones were excised aseptically from the hind limbs of rats and placed in high-glucose DMEM after removing the parenchyma. After the knee joint end of each bone was removed using sterile scissors to create a hole, the bone marrow was flushed from the shaft with DMEM using a 26 gauge needle. The marrow solution was harvested by $5000 \mathrm{rpm}$ centrifugation and aspiration of the supernatant, then the precipitate was resuspended in DMEM (supplemented with 10\% fetal bovine serum, $2 \mathrm{mM}$ glutamine, $100 \mathrm{U} / \mathrm{mL}$ penicillin, and $100 \mathrm{~g} / \mathrm{mL}$ streptomycin), and seeded into two $25 \mathrm{~cm}$ tissue culture flasks. After 36 hours, the flasks were rinsed three times with phosphatebuffered saline to remove the nonadherent cells. The medium was exchanged every three days throughout the studies. Twenty-four hours before the transfection experiments, adherent cells were rinsed with phosphate-buffered saline, trypsinized, and seeded in 24-well plates with complete DMEM without antibiotics. Cells were incubated at $37^{\circ} \mathrm{C}$ in a fully humidified atmosphere of $5 \% \mathrm{CO}_{2}$.

\section{MTT assay}

The rat mesenchymal stem cells were seeded in 96-well plates at an initial density of 5000 cells/well in $200 \mu \mathrm{L}$ of complete DMEM and cultured for 24 hours prior to adding PEG-PEI. The growth medium was replaced by complete DMEM containing different amounts of copolymers corresponding to delivery of $1 \mu \mathrm{g}$ of plasmid. Each concentration was replicated in three wells. Cells incubated without treatment were considered as controls, and cell viability values were set at $100 \%$. After incubation for four, eight, 12 , and 24 hours, respectively, the medium was changed to normal culture medium. Cells were incubated for another 48 hours. For cell viability assay, $20 \mu \mathrm{L}$ of sterile, filtered MTT stock solutions in phosphate-buffered saline ( $5 \mathrm{mg} / \mathrm{mL}$ ) was added to each well. After four hours, the unreacted dye was removed, and the formazan crystals were dissolved with $150 \mu \mathrm{L}$ of dimethyl sulfoxide. After gentle agitation for five minutes, the absorbance was read at $570 \mathrm{~nm}$ using a DU730 nucleic acid/protein analyzer (Beckman Coulter, Brea, CA).

\section{Wound and healing assay}

The rat mesenchymal stem cells were plated on six-well plates until they reached a confluence of $80 \%-90 \%$ with complete DMEM containing PEG-PEI $14 \mu \mathrm{g} / \mathrm{mL}$. A cell scraper was used to prepare a scratch across the layer of rat mesenchymal stem cells, as described previously by Faber-Elman et al. ${ }^{31}$ Rat mesenchymal stem cells were incubated at 0 , two, four, and eight hours after scratching, and the time-dependent percentages of the scratched area were calculated.

\section{Stem cell differentiation assay}

After being incubated in complete DMEM containing PEG-PEI $14 \mu \mathrm{g} / \mathrm{mL}$, the multilineage differentiation potential of the rat mesenchymal stem cells was assessed by testing their ability to differentiate into adipocytes and osteoblasts. Briefly, adipocyte and osteoblast differentiation was achieved after one week of culture of rat mesenchymal stem cells with adipogenic and osteogenic medium, respectively (Cyagen Biosciences, China). Oil-red-O and silver nitrate were used to identify the adipocytes and osteoblasts, respectively. 


\section{Gene transfection experiments}

The rat mesenchymal stem cells were seeded in six-well plates at a density of $2 \times 10^{5}$ cells per well, and cultured about 24 hours before transfection until they reached $70 \%-80 \%$ confluence. Plasmid $4 \mu \mathrm{g}$ was utilized for making a series of N/P ratios. The plasmid-encapsulated PEG-PEI complexes were prepared at N/P ratios of 0-50, and the cationic liposome (Lipofectamine)/ plasmid complexes were used as controls. Cells were incubated for eight hours with each complex. The cells were then washed and replated with complete DMEM and incubated at $37^{\circ} \mathrm{C}$ in $5 \% \mathrm{CO}_{2}$ atmosphere for 48 hours. The expression of pEGFP-C1 was observed by fluorescence microscopy (Nikon, Tokyo, Japan). Fluorescence was detected using $520 \mathrm{~nm}$ and $570 \mathrm{~nm}$ band pass filters for pEGFP-C1. The transfection efficiency of cells expressing pEGFP-C1 was determined using a FACS Aria $^{\mathrm{TM}}$ System from Becton-Dickinson (San Jose, CA). After being photographed by fluorescence microscopy, the cells were washed with phosphate-buffered saline and collected with a cell scraper and resuspended in phosphate-buffered saline for flow cytometry assay. Fluorescence parameters from approximately 10,000 cells were acquired, and transfection experiments were carried out in triplicate. Data analysis was carried out by using the WinMDI program.

\section{Interaction of plasmid-encapsulated PEG-PEl and rat mesenchymal stem cells}

The rat mesenchymal stem cells were seeded on cover slips and incubated with plasmid-encapsulated PEG-PEI for six hours. The rat mesenchymal stem cells were then washed with phosphate-buffered saline, fixed with $2.5 \%$ glutaraldehyde for 15 minutes, washed with distilled water, and dried at room temperature. The samples were scanned with a UL20B silicon probe on atomic force microscopy (Autoprobe CP Research, Thermomicroscopes, Goleta, CA) and analyzed by atomic force microscopy original software (IP2.1). The measurements were carried out in contact mode.

\section{Results and discussion Synthesis and characterization of PEG-PEI copolymer}

On Fourier transform infrared spectrum analysis of the PEG-PEI copolymer (shown in Figure 1), strong absorption around $1657 \mathrm{~cm}^{-1}$ appeared and was attributed to amide linkage, and a strong and broad peak around $3400 \mathrm{~cm}^{-1}$ was attributed to the characteristic absorption of amines. These results indicated that polyethylene glycol was grafted onto the polyethylenimine chains through amide linkage.

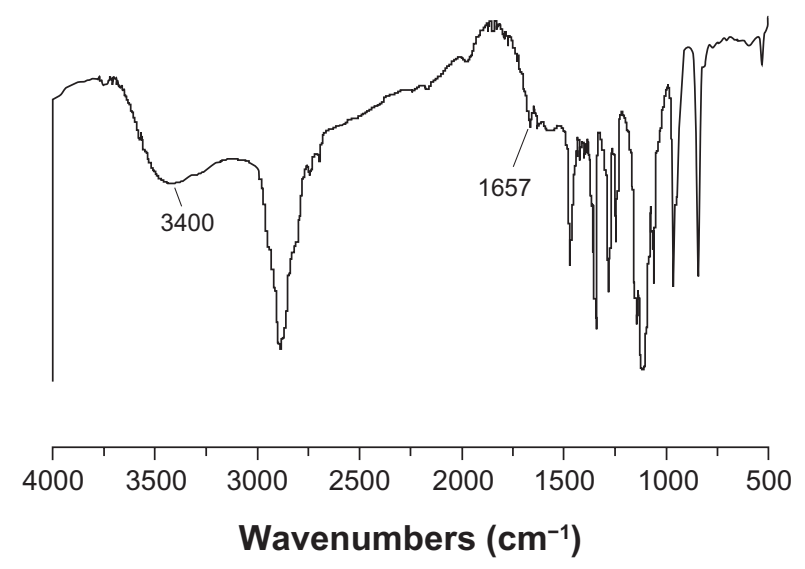

Figure I Fourier transform infrared spectra of polyethylene glycol-grafted polyethylenimine.

Note: A strong absorption around $1657 \mathrm{~cm}^{-1}$ attributed to the amide linkage appeared, and the strong and broad peak around $3400 \mathrm{~cm}^{-1}$ was attributed to the characteristic absorption of amines. These results indicated that polyethylene glycol was grafted on to polyethylenimine chains by amide linkage.

The ${ }^{1} \mathrm{H}-\mathrm{NMR}$ spectrum of the PEG-PEI graft copolymer is shown in Figure 2. Strongly characteristic peaks of polyethylene glycol and polyethylenimine residues at approximately $3.65 \mathrm{ppm}$ (peak B) and about $2.65 \mathrm{ppm}$ (peaks D and E), respectively, were observed. ${ }^{1} \mathrm{H}-\mathrm{NMR}$ spectroscopy further demonstrated that polyethylenimine was conjugated to the polyethylene glycol chains. The graft density of polyethylene glycol onto polyethylenimine was thus calculated to be four from the integral values of peak B and peaks D and E, using the known molecular weights of polyethylene glycol $(2 \mathrm{kDa})$ and polyethylenimine $(25 \mathrm{kDa})$.

\section{Toxicity and biocompatibility of PEG-PEI copolymer}

The superior transfection efficiency was based on cell viability. The cytotoxicity of PEG-PEI was related to copolymer concentration and incubation time in the culture medium. PEG-PEI showed minimal toxicity below a concentration of $8.75 \mu \mathrm{g} / \mathrm{mL}$, corresponding to condensed $4 \mu \mathrm{g}$ DNA at an N/P ratio of 25 in the six-well plate. Figure 3 shows the influence of rat mesenchymal stem cell viability on PEG-PEI concentration and incubation time. The results indicate that rat mesenchymal stem cells still maintained high viability after being incubated with PEG-PEI $14 \mu \mathrm{g} / \mathrm{mL}$ (corresponding to N/P 40) for 4-8 hours. However, cell viability attenuated remarkably when the cells were incubated, PEG-PEI concentration exceeded $14 \mu \mathrm{g} / \mathrm{mL}$, and incubation time was longer than eight hours. Because superior transfection efficiency depends on cell viability, cytotoxicity was the main cause of the transfection efficiency decrease at an N/P ratio of 50 . 


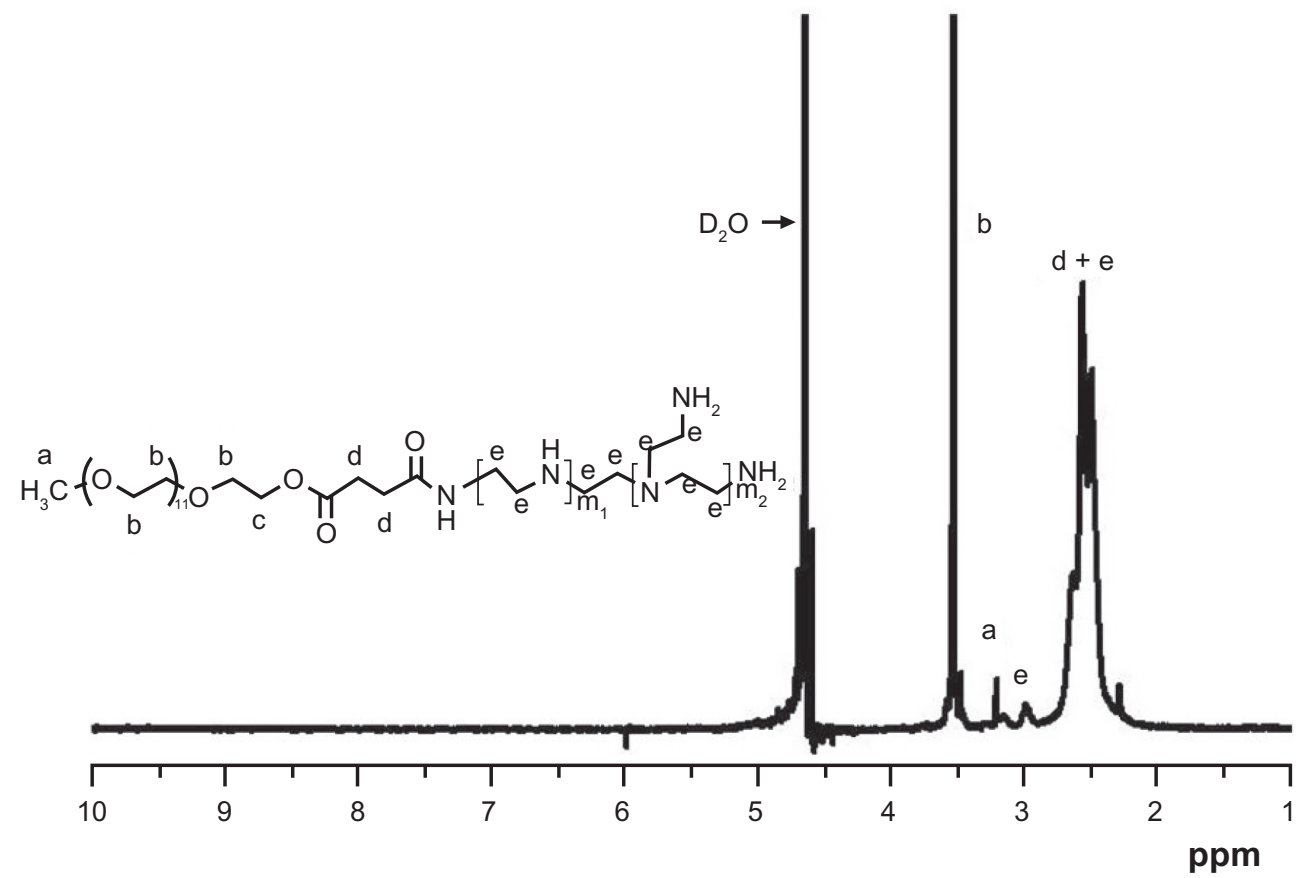

Figure 2 'H-NMR spectrum of PEG-PEl.

Note: PEG-PEI was synthesized by conjugating PEG-NHS onto polyethylenimine. 'H-NMR analysis of the dialyzed PEl-g-PEG revealed prominent chemical shifts of protons from polyethylene glycol $\left(-\mathrm{OCH}_{2} \mathrm{CH}_{2}-, 3.65\right.$ ppm; $\left.\mathrm{CH}_{3} \mathrm{O}-, 3.38 \mathrm{ppm}\right)$ and polyethylenimine $\left(-\mathrm{CH}_{2} \mathrm{CH}_{2} \mathrm{NH}-\right.$, 2.5-2.9 ppm), respectively, indicating that polyethylene glycol chains were successfully grafted onto polyethylenimine chains. Polyethylene glycol grafting density of polyethylenimine was 3.8 , as characterized by ' $\mathrm{H}-\mathrm{NMR}$.

Abbreviations: 'H-NMR, Hydrogen-I High resolution NMR; PEG-PEI, polyethylene glycol-grafted polyethylenimine; PEG-NHS, polyethylene glycol-N-hydroxysuccinimide.

We also assessed whether the migration and differentiation ability of stem cells was influenced when they were incubated with PEG-PEI. The wound and healing assay was designed to simulate the ability of stem cells to reconstruct a tissue. Rat mesenchymal stem cells incubated with culture medium containing PEG-PEI $14 \mu \mathrm{g} / \mathrm{mL}$ for eight hours migrated to the scratched area and resettled (Figure 4). The migration velocity of rat mesenchymal stem cells incubated with PEG-PEI for less than four hours

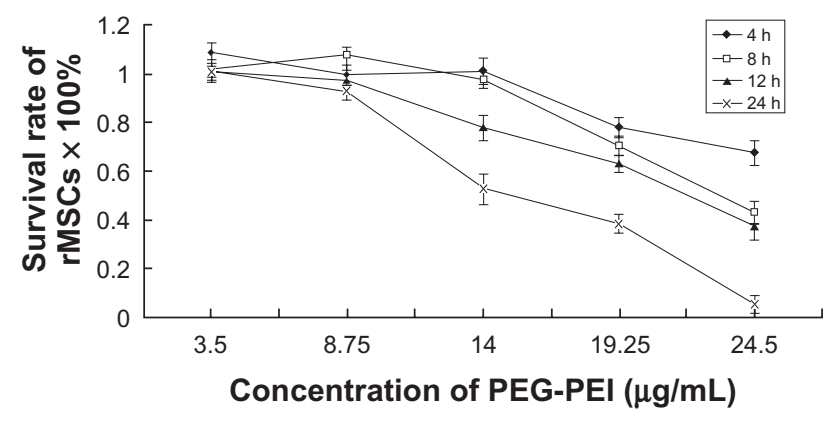

Figure 3 Influence of the viability of rat mesenchymal stem cells on PEG-PEI concentration and incubation time.

Note: The cells were treated with various concentrations of PEG-PEl for four, eight, 12, and 24 hours. Cell viability was determined by MTT assay. Incubated with PEGPEI I $4 \mu \mathrm{g} / \mathrm{mL}$ (corresponding to an N/P ratio of 40 ) for 4-8 hours, rat mesenchymal stem cells maintained high viability. The percentages of viable rat mesenchymal stem cells are shown. Values are the mean \pm standard deviation $(n=3)$.

Abbreviations: PEG-PEl, polyethylene glycol-grafted polyethylenimine; rMSCs, rat mesenchymal stem cell. did not change significantly compared with those incubated with DMEM. This incubation time-dependent regularity was consistent with that of the cell viability test. Furthermore, after incubation with PEG-PEI $14 \mu \mathrm{g} / \mathrm{mL}$ for eight hours, the rat mesenchymal stem cells were induced to differentiate into adipocytes and osteoblasts. The N/P ratio of 40 was considered to be safe for stem cells of multiple potency for differentiating to adipocytes and osteoblasts (Figure 5). In summary, the PEG-PEI copolymer exhibited low toxicity and good biocompatibility at a concentration of $14 \mu \mathrm{g} / \mathrm{mL}$.

\section{Properties of plasmid-encapsulated PEG-PEl nanoparticles}

To demonstrate the interaction between the positive PEG-PEI and the negative plasmid, a gel retardation assay was performed using electrophoresis. A typical result obtained during these electrophoresis experiments for the copolymer is presented in Figure 6A. Gel electrophoresis showed that PEG-PEI completely bound with plasmid at an N/P ratio of 3. Moreover, PEG-PEI condensed plasmid to form stable nanoparticles $100-200 \mathrm{~nm}$ in diameter at an N/P ratio of 15 (Figure 6B). In order to obtain nanoparticles effective for packing and delivery of plasmid, an N/P ratio $>15$ was chosen. Plasmid-encapsulated PEG-PEI nanoparticles with 


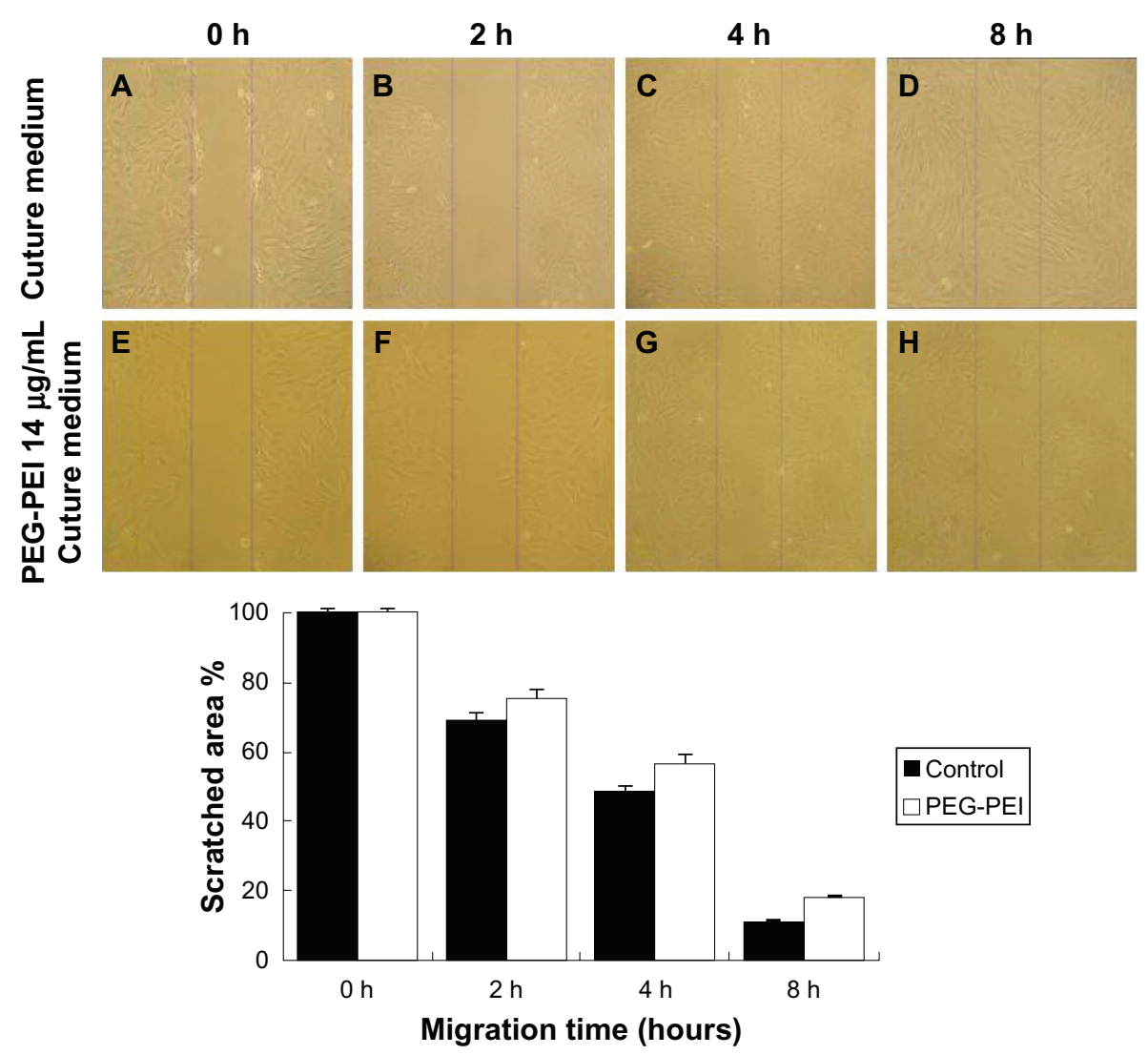

Figure 4 Wound and healing assay for rat mesenchymal stem cells.

Note: The confluent cells incubated with complete Dulbecco's modified Eagle's medium (A, B, C, D) or culture medium containing PEG-PEI I4 $\mu$ g/mL (E, F, G, H) were scratched by a cell scraper $(\mathbf{A}, \mathbf{E})$, and cultured for two $(\mathbf{B}, \mathbf{F})$, four $(\mathbf{C}, \mathbf{G})$, or eight $(\mathbf{D}, \mathbf{H})$ hours. After scratching, the surrounding cells migrated into the scratched area (time after scratching is indicated; original magnification $\times 100$ ). The time-dependent percentages of the residual scratched area were calculated under control conditions and in the presence of PEG-PEI $14 \mu \mathrm{g} / \mathrm{mL}$. When incubated with PEG-PEI for less than four hours, the migration velocity of the rat mesenchymal stem cells displayed insignificant changes. Values are the mean \pm standard deviation ( $n=3$ independent experiments).

$* P<0.05$ for rat mesenchymal stem cells incubated with PEG-PEI over four hours versus control group.

Abbreviation: PEG-PEI, polyethylene glycol-grafted polyethylenimine.

low toxicity and good compatibility for gene delivery are anticipated to achieve a long circulation time in blood.

\section{Gene transfection efficiency of plasmid- encapsulated PEG-PEI nanoparticles}

Mesenchymal stem cells are attractive targets in gene therapy for several human diseases. However, their ability to internalize and express exogenous DNA via nonviral gene delivery vehicles has been poorly investigated so far. Although the feasibility of using liposome and other lipid-based gene carriers $^{32}$ for transfecting many cell lines has been confirmed, there has been little research reported on cationic copolymer PEG-PEI-mediated transfection in stem cells. Here, we evaluated the transfection efficiency of PEG-PEI for delivering plasmid to rat mesenchymal stem cells. Passage 2-4 rat mesenchymal stem cells were used for the transfection experiments. The cationic liposome is a commercial nonviral gene delivery reagent and has been commonly used in transfecting many cell lines, so the transfection efficacy of cationic liposome was used as a positive control.

Forty-eight hours after transfection, the green fluorescence of the enhanced green fluorescent protein (EGFP) was observed qualitatively using fluorescence microscopy and
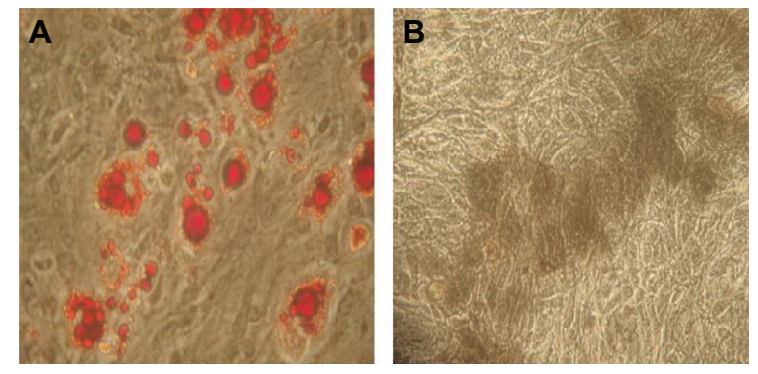

Figure $\mathbf{5}$ The multilineage potential of rat mesenchymal stem cells after incubation with the copolymer.

Note: After incubating with PEG-PEI $14 \mu \mathrm{g} / \mathrm{mL}$ for eight hours, rat mesenchymal stem cells were induced to differentiate into adipocytes ( $\mathbf{A}$ red cells) and osteoblasts (B black cells). Original magnification $\times 400$.

Abbreviation: PEG-PEl, polyethylene glycol-grafted polyethylenimine. 


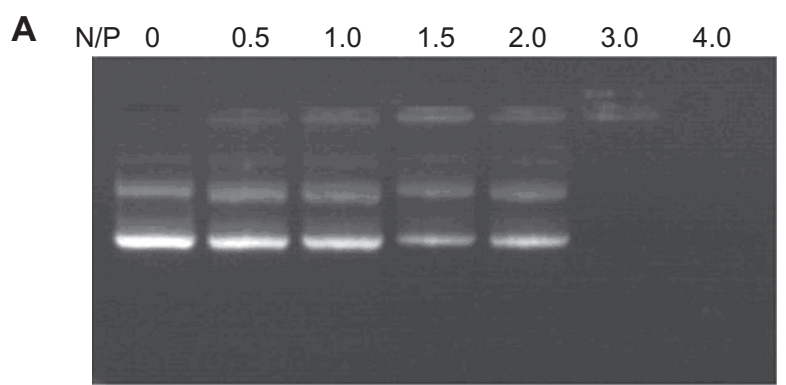

B

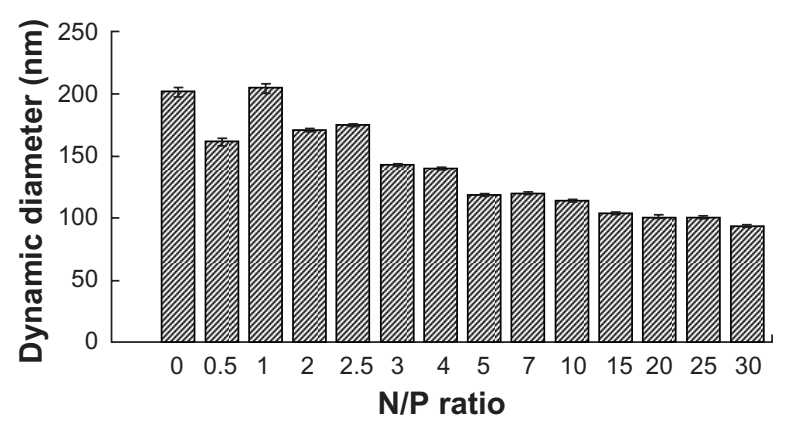

Figure 6 Electrophoretic migration and dynamic diameter distribution of PEG-PEI/EGFP-CI nanoparticles at various N/P ratios.

Note: To condense I $\mu \mathrm{g}$ DNA, PEG-PEI/pEGFP-Cl complexes were prepared at a series of N/P ratios. A) Agarose gel electrophoresis image showing that PEG$\mathrm{PEI}$ completely bound with pEGFP-CI at an N/P ratio of 3. B) Dynamic diameter distribution showing that PEG-PEI condensed PEGFP-CI to form nanoparticles in the $100-150 \mathrm{~nm}$ diameter range at an N/P ratio of I5. The particle diameters of the nanoparticles decreased further when the N/P ratio was over 10 and were stable when over 20. Values are the mean \pm standard deviation $(n=3)$.

Abbreviations: PEG-PEI, polyethylene glycol-grafted polyethylenimine; EGFP, enhanced green fluorescent protein.

flow cytometry. No green fluorescent protein expression on naked plasmid was observed under the fluorescence microscope (data not shown), whereas the cationic liposome/ pEGFP-C1 and the PEG-PEI/pEGFP-C1 nanoparticles produced green fluorescent cells after gene transfection (Figures 7A and 7B). In the same area of visual field, the number of green fluorescent cells of the PEG-PEI/pEGFP-C1 nanoparticle group was nearly double than that of the cationic liposome/pEGFP-C1 group.

The exact percentages of green fluorescent cells were then counted by flow cytometry (Figures 7C and 7D). Transfection efficiencies were compared in the following manner: rat mesenchymal stem cells incubated with cationic liposome/EGFP-C1 was the control group, and rat mesenchymal stem cells incubated with PEG-PEI/EGFP-C1 at N/P ratios of $10,20,30,40$, and 50 comprised the experimental groups. At the optimal N/P ratio of 40, the delivery efficacy (15\%-21\%) of PEG-PEI complexes in rat mesenchymal stem cells is higher than the delivery efficacy $(8 \%-15 \%)$ of cationic liposomes. These results suggest that PEG-PEI is a valid gene delivery agent and has better transfection efficacy in rat mesenchymal stem cells than does the cationic liposome.
Moreover, the increase in the N/P ratio of PEG-PEI to DNA resulted in increased gene expression in rat mesenchymal stem cells, but the transfection efficacy degraded remarkably at an N/P ratio of 50 . Considering the cytotoxicity of PEG-PEI concentrations above $14 \mu \mathrm{g} / \mathrm{mL}$, cell death and limited cell viability were the main causes of the lower transfection efficiency at an N/P ratio of 50 .

Our results for the gene transfection efficiency of plasmid-encapsulated PEG-PEI nanoparticles is in agreement with that previously reported. ${ }^{33-36}$ The feasibility of using polyethylenimine for transfection of many cell lines, in addition to liposomal and other lipid-based carriers, has been confirmed, ${ }^{33}$ but several researchers have demonstrated that it is difficult for polyethylenimine to obtain higher transfection efficiency than a viral vehicle. ${ }^{34-36}$ Farrell et $\mathrm{al}^{34}$ reported that the 48-hour transfection efficiency of polyethylenimine-mediated gene delivery to rat mesenchymal stem cells is below $4 \%$ at an N/P ratio of 7 . Ahn et $\mathrm{al}^{35}$ reported that introducing DNA/PEI nanoparticles into rat mesenchymal stem cells resulted in $2 \%-10 \%$ transfection efficiency. In human adipose-derived stem cells, polyethylenimine produced the highest transfection of $19 \%$ at an N/P ratio of 8 , which was superior to that achieved by Lipofectamine. ${ }^{36}$

Cell internalization is correlated with the buffer action of the cell membrane reservoir, the functioning of the cytoskeleton, and the location of the nanomicrocapsules within cells. The interaction between nanomicrocapsules and various cell lines may be very different. The mechanical properties of stem cells, including cell membrane tension and adhesion, and cytoskeleton molding and elasticity, are different from those of terminally differentiated cells..$^{37,38}$ Moreover, Farrell et $\mathrm{al}^{34}$ found that less than $10 \%$ of PEI/ DNA or poly-L-lysine/DNA intake by mesenchymal stem cells occurred in the nuclei. It is suggested that relatively low gene internalization and expression in rat mesenchymal stem cells during cationic polymer-mediated gene delivery might be caused by their low uptake capacity and the distinct cytoskeleton mechanism involved in cellular trafficking. ${ }^{39}$

Superior transfection efficiency was obtained at the optimized N/P ratio of 40 , which was much more than the N/P ratio of 15 needed for stable nanoparticle formation, implying that there was much dissociative PEG-PEI in the culture medium. Dissociative PEG-PEI did not pack and deliver plasmid, but probably enhanced the permeability of the cell membrane, activated cell membrane components, and indirectly increased endocytosis. ${ }^{40}$ 
A

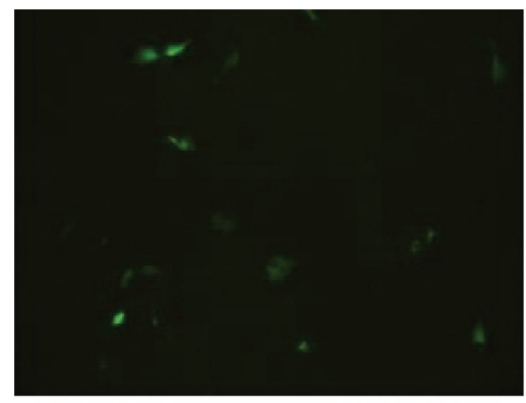

C

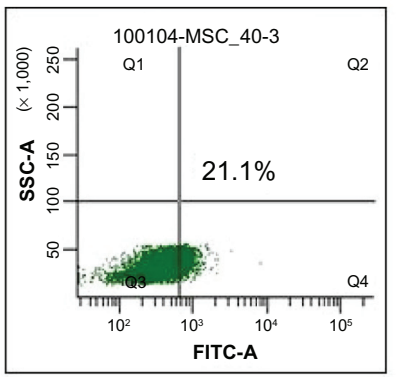

B

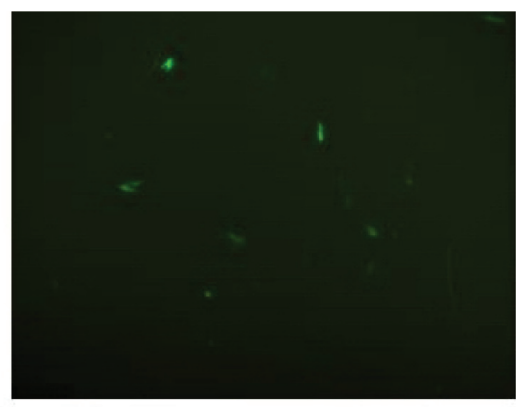

D

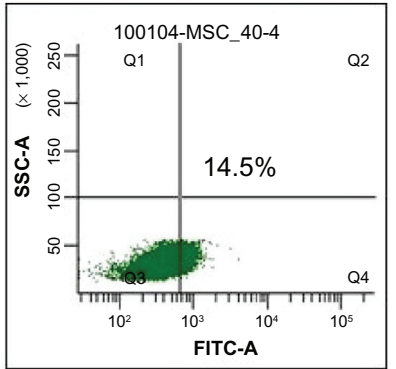

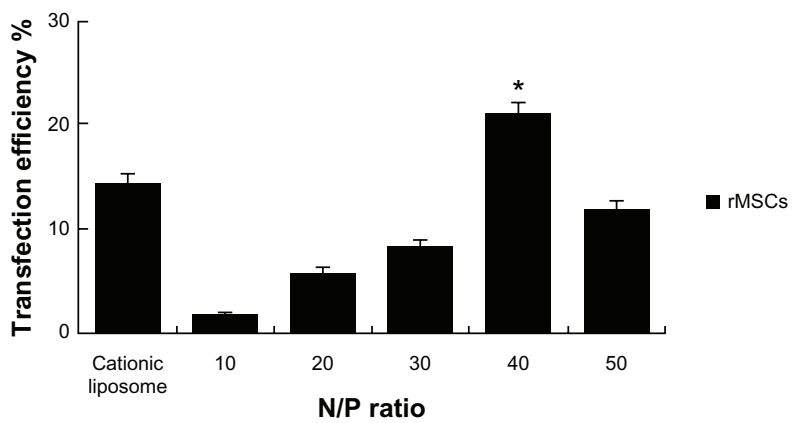

Figure 7 EGFP-CI encapsulated by different carriers for gene delivery into rat mesenchymal stem cells.

Note: Fluorescence microscopy was used to observe the transfection efficiency of PEG-PEI-mediated plasmid delivery in rat mesenchymal stem cells. A) PEG-PEI and B) liposome. Typical samples of rat mesenchymal stem cells showed 8\%-15\% EGFP expression when incubated with cationic liposome/EGFP-CI (D), and showed I5\%-2I\% EGFP expression when incubated with PEG-PEI/pEGFP-CI at the optimal N/P ratio of 40 (C). Original magnification $\times 100$. The transfection efficiency tendency of rat mesenchymal stem cells incubated with cationic liposome/EGFP-CI or PEG-PEI/EGFP-CI at N/P ratios of 10, 20, 30, 40, and 50 are shown. An increase in the N/P ratio of PEG-PEI to DNA resulted in an increase of gene expression in rat mesenchymal stem cells, but the transfection efficacy degraded remarkably at an N/P ratio of 50 . Values are the mean \pm standard deviation $(n=3)$.

$* P<0.05$ for N/P 40 versus N/P I0, 20, 30, and 50, and cationic liposome.

Abbreviations: EGFP, enhanced green fluorescent protein; FITC, Fluoreceine-isothiocyanate: PEG-PEI, polyethylene glycol-grafted polyethylenimine; rMSCs, rat mesenchymal stem cells; SSC, Side scatter.

\section{Interaction of nanoparticles and rat mesenchymal stem cells}

To highlight the interactions between plasmid-encapsulated PEG-PEI microcapsules and the cell membrane, atomic force microscopy were used to scan the ultrastructure of rat mesenchymal stem cells in the $1-70 \mu \mathrm{m}$ range. Figures $8 \mathrm{~A}$ and $8 \mathrm{~B}$ showed a typical rat mesenchymal stem cell which is fusiform-shaped with a well-arranged cytoskeleton. Although some small introcessions can be detected, the surface of the nuclear region and the boundary of the cell are relatively smooth (Figures 8C and 8D).

After six hours' incubation of plasmid-encapsulated PEG-PEI, nanoparticles $200-400 \mathrm{~nm}$ in diameter adsorb onto the cell membrane (Figures $8 \mathrm{E}-8 \mathrm{H}$ ) by concentrating negatively charged plasmid onto the positively charged nanoparticles. Some samples were washed with phosphatebuffered saline and cultured for another six hours. Some biggish hollows were observed (Figures 8I-8L). Compared with the pits on the control cells, the hollows are fewer, deeper, and presumed to reflect cytophagocytosis of the plasmid-encapsulated PEG-PEI nanoparticles (Figures 8M and $8 \mathrm{~N}$ ). The interactions between the plasmid-encapsulated PEG-PEI and the cytoskeleton of rat mesenchymal stem cells will be investigated further in the future. New insights into the behavior of nanoparticles might guide improvements in vector design for clinical application, such as improved interaction with the cytoskeleton by promoting binding of motor proteins (see Figure 8). 

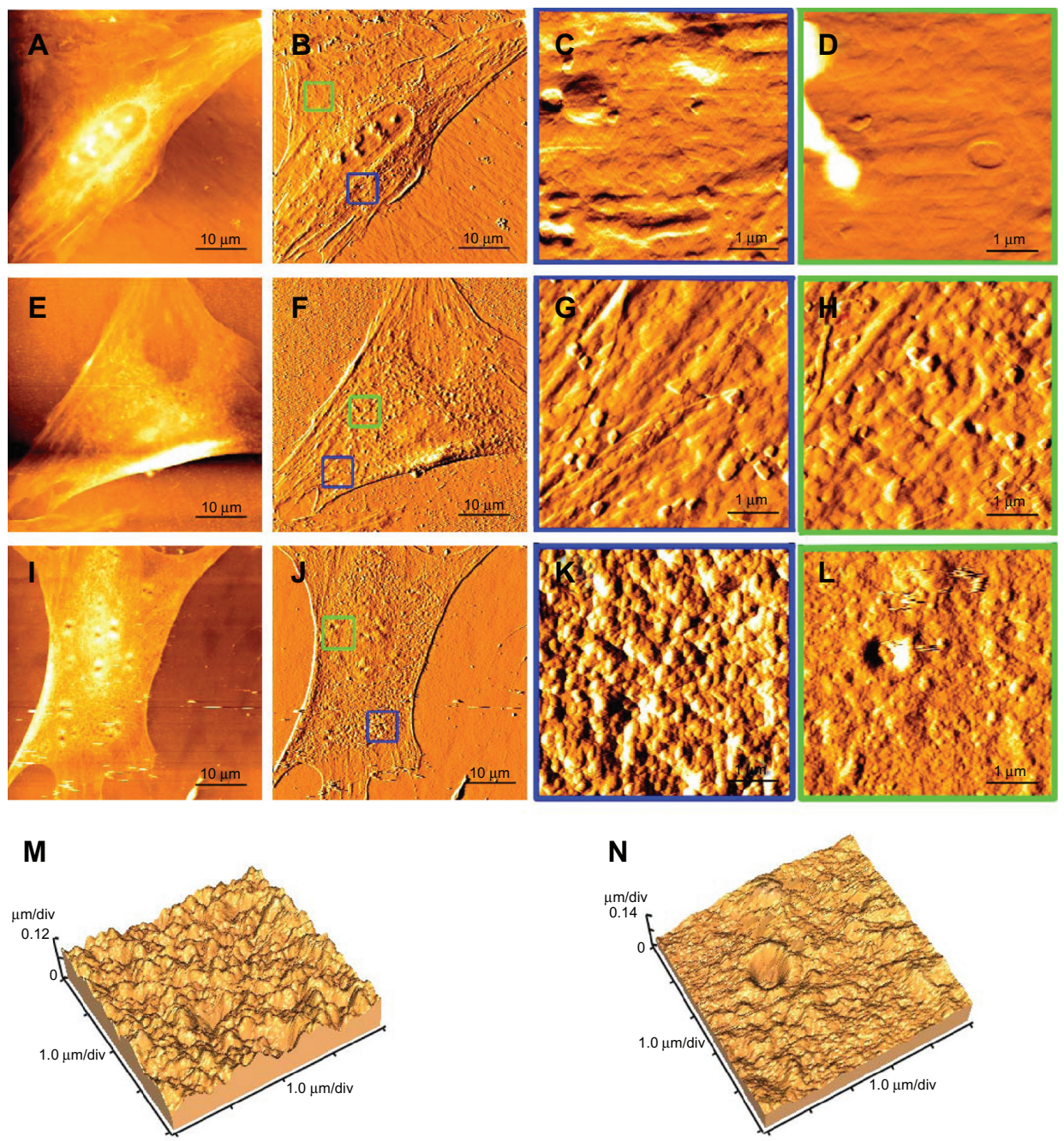

Figure 8 Cellular uptake of plasmid-encapsulated PEG-PEI microcapsules observed by atomic force microscopy.

Note: The samples were scanned in the range of I-70 $\mu \mathrm{m}$ with a UL20B silicon probe on atomic force microscopy and analyzed by original software (IP2.I). The measurements were carried out in contact mode. Typical passage 4 rat mesenchymal stem cells comprised the controls (A, B), and the surface of the nuclear region and the boundary of the cell are relatively smooth (C, D). After six hours of plasmid-encapsulated PEG-PEl incubation, nanoparticles of $200-400$ nm diameter adsorb onto the cell membrane (E, F). Some samples were washed with phosphate-buffered saline and cultured for another six hours. Some biggish hollows can be observed (G, H, I, and J). Simulation at three dimensions of ( $\mathbf{I}$ and $\mathbf{J})$ are showed in ( $\mathbf{K}$ and $\mathbf{L})$ separately.

Abbreviation: PEG-PEI, polyethylene glycol-grafted polyethylenimine.

\section{Conclusion}

Our results demonstrate that polyethylenimine modified with polyethylene glycol sufficiently condensed plasmid into nanoparticles. After optimizing the N/P ratio for plasmid delivery, PEG-PEI/pEGFP-C1 nanoparticles displayed low cytotoxicity, good solubility, and compatibility with serum. The migration velocity and multiple differentiation potency of rat mesenchymal stem cells were not affected after exposure to the copolymers during 48 hours of transfection. PEG-PEI/DNA at an N/P ratio of 40 obtained the highest efficiency (21\%) in rat mesenchymal stem cells, which was better than for cationic liposomes.

Our data indicate that PEG-PEI is a valid gene vehicle and an even better choice for transfecting rat mesenchymal stem cells than conventional liposomes. PEG-PEI is a representative synthetic gene vector and displays superiority in many situations. Biocompatibility was guaranteed by dense polyethylene glycol shells, which endowed the nanoparticles with water solubility and prevented their interaction with serum protein in the culture medium. At an optimum N/P ratio, PEG-PEI also may have the advantage of lower toxicity and better adsorption properties than liposomes. This makes PEG-PEI a promising gene vector in vivo, with PEGylation preventing aggregation of PEI/DNA complexes under physiological conditions.

\section{Acknowledgments}

This work was supported by the Sun Yat-sen University Postgraduates' Training Project, the Yi-xian Innovators' 
Training Project by Outstanding Mentor(s) at Sun Yat-sen University (NO:50000-3126203), the Graduates' internationally cooperated research project of Sun Yat-sen University (2008-2009), the National Natural Science Foundation of China, and the Science and Technology Planning Project of Guangdong Province, China.

\section{Disclosure}

The authors report no conflicts of interest in this work.

\section{References}

1. Lin Z, Willers $\mathrm{C}, \mathrm{Xu} \mathrm{J}$, Zheng MH. The chondrocyte: Biology and clinical application. Tissue Eng. 2006;12(7):1971-1984.

2. Pereira RF, Halford KW, O'Hara MD, et al. Cultured adherent cells from marrow can serve as long-lasting precursor cells for bone, cartilage, and lung in irradiated mice. Proc Natl Acad Sci. 1995;92(11): 4857-4861.

3. Azizi SA, Stokes D, Augelli BJ, DiGirolamo C, Prockop DJ. Engraftment and migration of human bone marrow stromal cells implanted in the brains of albino rats: Similarities to astrocyte grafts. Proc Natl Acad Sci. 1998;95(7):3908-3913.

4. Chen J, Li Y, Wang L, Lu M, Zhang X, Chopp M. Therapeutic benefit of intracerebral transplantation of bone marrow stromal cells after cerebral ischemia in rats. $J$ Neurol Sci. 2001;189(1-2):49-57.

5. Gou S, Wang C, Liu T, et al. Spontaneous differentiation of murine bone marrow-derived mesenchymal stem cells into adipocytes without malignant transformation after long-term culture. Cells Tissues Organs. 2010;191(3):185-192.

6. Krebsbach PH, Kuznetsov SA, Bianco P, Robey PG. Bone marrow stromal cells: Characterization and clinical application. Crit Rev Oral Biol Med. 1999;10(2):165-181.

7. Li Y, Chen J, Chen XG, et al. Human marrow stromal cell therapy for stroke in rat: Neurotrophins and functional recovery. Neurology. 2002;59(4):514-523.

8. Aggarwal S, Pittenger MF. Human mesenchymal stem cells modulate allogeneic immune cell responses. Blood. 2005;105(4):1815-1822.

9. Wang Y, Deng Y, Zhou GQ. SDF-1alpha/CXCR4-mediated migration of systemically transplanted bone marrow stromal cells towards ischemic brain lesion in a rat model. Brain Res. 2008;1195: 104-112.

10. Chen J, Li Y, Wang L, et al. Therapeutic benefit of intravenous administration of bone marrow stromal cells after cerebral ischemia in rats. Stroke. 2001;32(4):1005-1011.

11. Dai F, Shi D, He W, et al. hCTLA4-gene modified human bone marrowderived mesenchymal stem cells as allogeneic seed cells in bone tissue engineering. Tissue Eng. 2006;12(9);2583-2590.

12. Bivalacqua TJ, Deng W, Kendirci M, et al. Mesenchymal stem cells alone or ex vivo gene modified with endothelial nitric oxide synthase reverse age-associated erectile dysfunction. Am J Physiol Heart Circ Physiol. 2007;292(3);H1278-H1290.

13. Cheng Z, Ou L, Zhou X, et al. Targeted migration of mesenchymal stem cells modified with CXCR4 gene to infarcted myocardium improves cardiac performance. Mol Ther. 2008;16(3):571-579.

14. Breen A, Strappe P, Kumar A, O’Brien T, Pandit A. Optimization of a fibrin scaffold for sustained release of an adenoviral gene vector. J Biomed Mater Res A. 2006;78(4):702-708.

15. Palmer JA, Branston RH, Lilley CE, et al. Development and optimization of herpes simplex virus vectors for multiple long-term gene delivery to the peripheral nervous system. J Virol. 2000;74(12): 5604-5618.

16. Nimesh S, Kumar R, Chandra R. Novel polyallylamine-dextran sulfateDNA nanoplexes: Highly efficient non-viral vector for gene delivery. Int J Pharm. 2006;320(1-2):143-149.
17. Kim MS, Diamond SL. Controlled release of DNA/polyamine complex by photoirradiation of a solid phase presenting o-nitrobenzyl ether tethered spermine or polyethyleneimine. Bioorg Med Chem Lett. 2006; 16(21):5572-5575.

18. Su CJ, Liu YC, Chen HL, et al. Two-dimensional densely packed DNA nanostructure derived from DNA complexation with a low-generation poly(amidoamine) dendrimer. Langmuir. 2007;23(3):975-978.

19. Banerjee, P, Weissleder R, Bogdanov AJ. Linear polyethyleneimine grafted to a hyperbranched poly(ethylene glycol)-like core: A copolymer for gene delivery. Bioconjug Chem. 2006;17(1):125-131.

20. Kleemann E, Neu M, Jekel N, et al. Nano-carriers for DNA delivery to the lung based upon a TAT-derived peptide covalently coupled to PEG-PEI. J Control Release. 2005;109(1-3):299-316.

21. Akinc A, Thomas M, Klibanov AM, Langer R. Exploring polyethylenimine-mediated DNA transfection and the proton sponge hypothesis. J Gene Med. 2005;7(5):657-663.

22. Brunot C, Ponsonnet L, Lagneau C, Farge P, Picart C, Grosgogeat B. Cytotoxicity of polyethyleneimine (PEI), precursor base layer of polyelectrolyte multilayer films. Biomaterials. 2007;28(4):632-640.

23. Zhu W, Chen J, Cong X, Hu S, Chen X. Hypoxia and serum deprivationinduced apoptosis in mesenchymal stem cells. Stem Cells. 2006; 24(2):416-425.

24. Nguyen HK, Lemieux P, Vinogradov SV, et al. Evaluation of polyetherpolyethyleneimine graft copolymers as gene transfer agents. Gene Ther. 2000;7(2):126-138.

25. Wen Y, Pan S, Luo X, Zhang W, Shen Y, Feng M. PEG- and PDMAEGgraft-modified branched PEI as novel gene vector: Synthesis, characterization and gene transfection. J Biomater Sci Polym Ed. 2010; 21(8):1103-1126.

26. Weiss SI, Sieverling N, Niclasen M, et al. Uronic acids functionalized polyethyleneimine (PEI)-polyethyleneglycol (PEG)-graft-copolymers as novel synthetic gene carriers. Biomaterials. 2006;27(10): 2302-2312.

27. Merdan T, Kopecek J, Kissel T. Prospects for cationic polymers in gene and oligonucleotide therapy against cancer. Adv Drug Deliv Rev. 2002; 54(5):715-758.

28. Kircheis R, Wightman L, Wagner E. Design and gene delivery activity of modified polyethylenimines. Adv Drug Deliv Rev. 2001;53(3): 341-358.

29. Ogris M, Brunner S, Schüller S, Kircheis R, Wagner E. PEGylated DNA/transferrin-PEI complexes: Reduced interaction with blood components, extended circulation in blood and potential for systemic gene delivery. Gene Ther. 1999;6(4):595-605.

30. Wu Y, Wang W, Chen Y, et al. The investigation of polymer-siRNA nanoparticle for gene therapy of gastric cancer in vitro. Int $J$ Nanomedicine. 2010;5:129-136.

31. Faber-Elman A, Solomon A, Abraham JA, Marikovsky M, Schwartz M. Involvement of wound-associated factors in rat brain astrocyte migratory response to axonal injury: In vitro simulation. $J$ Clin Invest. 1996;97(1):162-171.

32. Park J, Ries J, Gelse K, et al. Bone regeneration in critical size defects by cell-mediated BMP-2 gene transfer: A comparison of adenoviral vectors and liposomes. Gene Ther. 2003;10(13):1089-1098.

33. Pochampally RR, Horwitz EM, DiGirolamo CM, Stokes DS, Prockop DJ. Correction of a mineralization defect by overexpression of a wild-type cDNA for COL1 A1 in marrow stromal cells (MSCs) from a patient with osteogenesis imperfecta: A strategy for rescuing mutations that produce dominant-negative protein defects. Gene Ther. 2005;12(14):1119-1125.

34. Farrell LL, Pepin J, Kucharski C, Lin X, Xu Z, Uludag H. A comparison of the effectiveness of cationic polymers poly-L-lysine (PLL) and polyethylenimine (PEI) for non-viral delivery of plasmid DNA to bone marrow stromal cells (BMSC). Eur J Pharm Biopharm. 2007;65(3): 388-397.

35. Ahn HH, Lee MS, Cho MH, et al. DNA/PEI nano-particles for gene delivery of rat bone marrow stem cells. Colloids Surf A Physicochem Eng Asp. 2008;313-314. 
36. Ahn HH, Lee JH, Kim KS, et al. Polyethyleneimine-mediated gene delivery into human adipose derived stem cells. Biomaterials. 2008; 29(15):2415-2422.

37. Settleman J. Tension precedes commitment - even for a stem cell. Mol Cell. 2004;14(2):148-150.

38. Thomas CH, Collier JH, Sfeir CS, Healy KE. Engineering gene expression and protein synthesis by modulation of nuclear shape. Proc Natl Acad Sci U S A. 2002;99(4):1972-1977.
39. Le Blanc K. Immunomodulatory effects of fetal and adult mesenchymal stem cells. Cytotherapy. 2003;5(6):485-489.

40. Hong S, Leroueil PR, Janus EK, et al. Interaction of polycationic polymers with supported lipid bilayers and cells: Nanoscale hole formation and enhanced membrane permeability. Bioconjug Chem. 2006;17(3):728-734.

\section{Publish your work in this journal}

The International Journal of Nanomedicine is an international, peerreviewed journal focusing on the application of nanotechnology in diagnostics, therapeutics, and drug delivery systems throughout the biomedical field. This journal is indexed on PubMed Central, MedLine CAS, SciSearch ${ }^{\circledR}$, Current Contents $® /$ Clinical Medicine, Journal
Citation Reports/Science Edition, EMBase, Scopus and the Elsevier Bibliographic databases. The manuscript management system is completely online and includes a very quick and fair peer-review system, which is all easy to use. Visit http://www.dovepress.com/ testimonials.php to read real quotes from published authors.

Submit your manuscript here: http://www.dovepress.com/international-journal-of-nanomedicine-journal 